УДК 556.3(1/9)

ПРОСТРАНСТВЕННОЕ РАСПРЕДЕЛЕНИЕ ВОДООБИЛЬНЫХ ЗОН, ПРИУРОЧЕННЫХ К ТЕРРИГЕННО-КАРБОНАТНОЙ ТОЛЩЕ В РАЙОНЕ ВЕРХНЕКАМЬЯ

\author{
Демина А.А., Катаев В.Н.
}

ФГБОУ ВО «Пермский государственный наџиональный исследовательский университет», Пермь, e-mail: aademina11@mail.ru

Рассматривается пространственное распределение водообильных зон в районе Верхнекамского месторождения калийных солей, приуроченных к надсолевым отложениям терригенно-карбонатной толщи и связанным с ней верхнесоликамским водоносным горизонтом. Представлены гидрогеологические условия территории исследования и проблемы изучения водообильных зон. Анализ гидрогеологических и других работ показал, что выделенные зоны терригенно-карбонатной толщи относятся к тектоногенным водообильным зонам. По пространственному расположению они однотипны и представляют собой локальные площадные зоны неглубокого заложения. По результатам картирования построена схема расположения водообильных зон терригенно-карбонатной толщи на площади Верхнекамского месторождения калийных солей (всего 44 зоны). Установлено, что наибольшее количество водообильных зон расположено в центральной, южной и западной частях месторождения. Показано расположение водообильных зон относительно региональных разломов, а также разрывных нарушений более мелкого порядка. Наиболее водообильные участки приурочены к тектоническим разрывным нарушениям (разломам) и долинам малых рек. С водообильными зонами разломов связаны многие водозаборы и крупные месторождения подземных вод Верхнекамья, эксплуатирующие верхнесоликамский водоносный горизонт. Высокая водообильность разломов подтверждается на участках, приуроченных к речным долинам. По результатам откачек из водозаборных скважин на Легчимском месторождении подземных вод, пробуренных в зонах разломов на разных элементах рельефа, наблюдается закономерное увеличение дебита скважин, расположенных в речных долинах, и минимальные значения дебита на междуречьях. Приводится разделение водообильных зон по пространственному положению относительно элементов рельефа. Рассмотрено влияние структурно-тектонических и геодинамических факторов на площадное расположение водообильных зон.

Ключевые слова: Пермский край, Верхнекамское месторождение солей, водообильные зоны, терригеннокарбонатная толща, верхнесоликамский водоносный горизонт, трещиноватость, разрывные нарушения

\title{
SPATIAL DISTRIBUTION OF THE HIGH WATER SATURATION ZONES OF TERRIGENOUS-CARBONATE THICKNESS WITHIN THE UPPER-KAMA AREA
}

\author{
Demina A.A., Kataev V.N. \\ Perm State National Research University, Perm,e-mail: aademina11@mail.ru
}

\begin{abstract}
Analyzed the spatial distribution of the high water saturation zones within the Upper-Kama salt deposit related to upper-salt deposit of terrigenous-carbonate thickness and associated with it Upper-Solikamsky aquifer. The hydrogeological conditions of the study area and problems of study high water saturation zones are presented. Analysis of the hydrogeological and over works showed that the isolated zones of terrigenous-carbonate thickness belong to tectonogenic high water saturation zones. By spatial location, they are of the same type and local area zones of shallow laying. By the results of mapping was built a scheme of the location of the high water saturation zones within the Upper-Kama salt deposit (44 zones in total). It was established that the largest number of the high water saturation zones is located in central, southern and western parts of the deposit. The location of the high water saturation zones relative to regional faults as well as breaking violations of a smaller order, is shown. The most high water zones are confined to tectonic fracturing (faults) and small river valleys. Many water intakes and large underground water deposits of Upper-Kama area, which operate the Upper-Solikamsky aquifer, are associated with high water saturation zones of faults. The high water abundance of faults is confirmed in areas confined to river valleys. According to the results of pumping out of water wells at the Legchimskoe undergroundwater deposit drilled in fault zones on different elements of the relief, there is a natural increase in well production located in river valleys and minimum production at the interfluves. The division of high water saturation zones by spatial position relative to relief elements is given. Influence of structural-tectonic and geodynamic factors on area location of high water saturation zones is considered.
\end{abstract}

Keywords: Perm Krai, Upper-Kama salt deposit, high water saturation zones, terrigenous-carbonate thickness, Upper-Solikamsky water-bearing horizon, fracture, breaking violation

Под понятием «водообильная зона» понимаются ограниченные участки земной коры, отличающиеся повышенной концентрацией подземных вод одного или нескольких водоносных горизонтов (комплексов) в результате тектонических, структурных, литологических, геоморфологических или других условий. Такие зоны представляют собой сложные гидро- геологические объекты в водоносных пластах, горизонтах, комплексах, обладают повышенными ресурсами подземных вод, в большинстве своем - пресных [1].

Изучение водообильных зон требует довольно длительного времени. На территории Пермского края и, в частности Верхнекамья, на протяжении более 50 лет проводятся поиски водообильных зон. Их изучением за- 
нимались многие исследователи - Н.Д. Буданов, Л.И. Шимановский, И.А. Печеркин, Г.К. Михайлов, Е.А. Иконников, А.В. Ревин, В.Н. Катаев, В.А. Шерстнев и др. Как правило, водообильные зоны выявляются и подтверждаются при проведении региональных гидрогеологических исследований и картографировании [1]. Большинство съемочных работ проводилось в 1960-1980 гг.

Цель исследования состоит в изучении пространственного распределения водообильных зон терригенно-карбонатной толщи в районе Верхнекамского месторождения калйиных солей (BКМС) относительно элементов разрывной тектоники, рельефа, а также площадного расположения зон.

\section{Материалы и методы исследования}

Территория характеризуется сложными гидрогеологическими условиями. По гидрогеологическому районированию площадь исследования расположена в Предуральской гидрогеологической области, Соликамском гидрогеологическом районе, который территориально соответствует Соликамской впадине [2]. В верхней части гидрогеологического разреза - в зоне активного водообмена - залегают преимущественно терригенные, карбонатные и сульфатные фациально-невыдержанные породы верхнего палеозоя. Воды зоны, как правило, пресные. Над соляными поднятиями мощность зоны активного водообмена составляет около 100 м, в депрессиях кровли соленосной толщи - до 200 м [2]. Формирование водообильных зон происходит под действием многих процессов, ведущую роль среди которых играют структурно-тектонические условия и геодинамическая (неотектоническая) активность, обуславливающие повышенную степень трещиноватости пород [1].

В последние годы все более острой становится проблема снабжения населения питьевой водой. Несмотря на то, что в современном хозяйственно-питьевом водоснабжении Пермского края преобладает использование поверхностных вод, крупные города Верхнекамья - Соликамск и Березники - для хозяйственно-питьевых нужд используют исключительно подземные воды. Исследование водообильных зон, как возможных месторождений подземных вод с относительно высокими гидрогеологическими параметрами, сталкивается с рядом проблем, не имеющих сегодня унифицированного решения. Это проблемы установления морфометрических параметров зоны, её качественного проявления в раз- личных литологических типах терригенных отложений, установления фильтрационных свойств различных частей зоны, проблемы установления механизма восполнения запасов воды, формирования их химического состава [3].

При проведении гидрогеологических съемочных работ в районе ВКМС в 19701980 гг. установлено и закартировано 44 водообильных зоны, приуроченные к верхнесоликамскому водоносному горизонту. В наиболее водообильных из них отмечаются дебиты родников до 990 л/с, скважин до 100 л/с и более.

\section{Результаты исследования и их обсуждение}

Интерпретация картографического материала съемочных работ позволила авторам построить схему расположения водообильных зон терригенно-карбонатной толщи на площади ВКМС (рис. 1).

Пликативная структура надсолевого комплекса пород соответствует структуре кровли соленосной толщи [2]. На площади месторождения большинство предполагаемых разрывных нарушений занимают в основном центральную и южную части (рис. 2).

Северная же часть месторождения отличается наиболее спокойным рельефом кровли соляной толщи. Наибольшее количество водообильных зон расположено именно в центральной и южной частях месторождения, а также они тяготеют к западной границе месторождения, правобережью р. Камы.

При сопоставлении рис. 1 и 2 становится очевидно, что большая часть водообильных зон терригенно-карбонатной толщи расположена в пределах влияния Красноуфимского и Боровицкого региональных разломов, а также приурочена к разрывным нарушениям более мелкого порядка (рис. 3).

Как правило, водообильные зоны приурочены к тектоническим разрывным нарушениям (разломам), представляющим собой линейные зоны трещиноватых и разуплотненных пород, где гидрогеологические параметры эксплуатационного горизонта много выше, чем на прилегающих площадях. Также они тяготеют к долинам малых рек и локализованы в узких линейных зонах шириной десятки и первые сотни метров [3].

С водообильными зонами разломов связаны многие водозаборы, расположенные на площади ВКМС и такие крупные месторождения подземных вод, как Верхнекамское и Легчимское. Все они эксплу- 
атируют верхнесоликамский водоносный горизонт. Следует отметить, что высокая водообильность разломов прослеживается не на всем их протяжении, а на отдельных участках, приуроченных к речным долинам. На междуречных пространствах (на склонах и водоразделах) разломы по водоносности не проявляются [4]. Это подтверждается и данными результатов откачек из водозаборных скважин на Легчимском месторождении подземных вод, представленных в таблице.

Разделение водообильных зон по пространственному положению относительно элементов рельефа приводится в ра- боте В.А. Шерстнева [5]. Он различает водообильные зоны водораздельных пространств, склонов и речных долин. Наиболее широким распространением пользуются водообильные зоны склонов и речных долин. Водообильные зоны водораздельных пространств встречаются довольно редко. На территории ВКМС практически все водообильные зоны терригенно-карбонатной толщи приурочены к речным долинам. Исключением является Селянское месторождение подземных вод и водозабор Соликамского калийного рудоуправления - 3 (СКРУ-3), расположенный на водоразделе рек Усолки и Селянки.

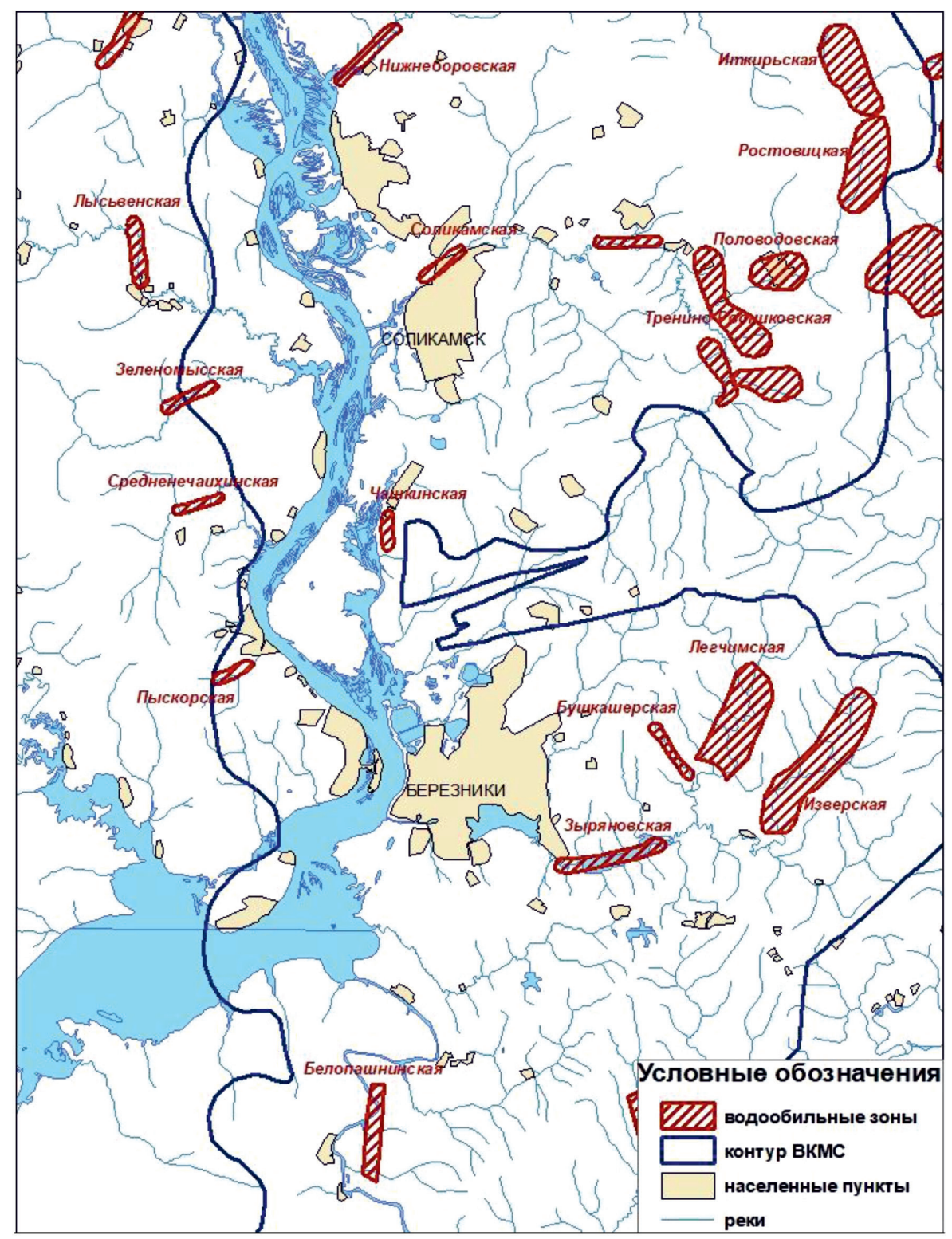

Рис. 1. Фрагмент схемы распределения водообильных зон терригенно-карбонатной толщи на территории ВКМС (по даннылм гидрогеологических съемочных работ) 


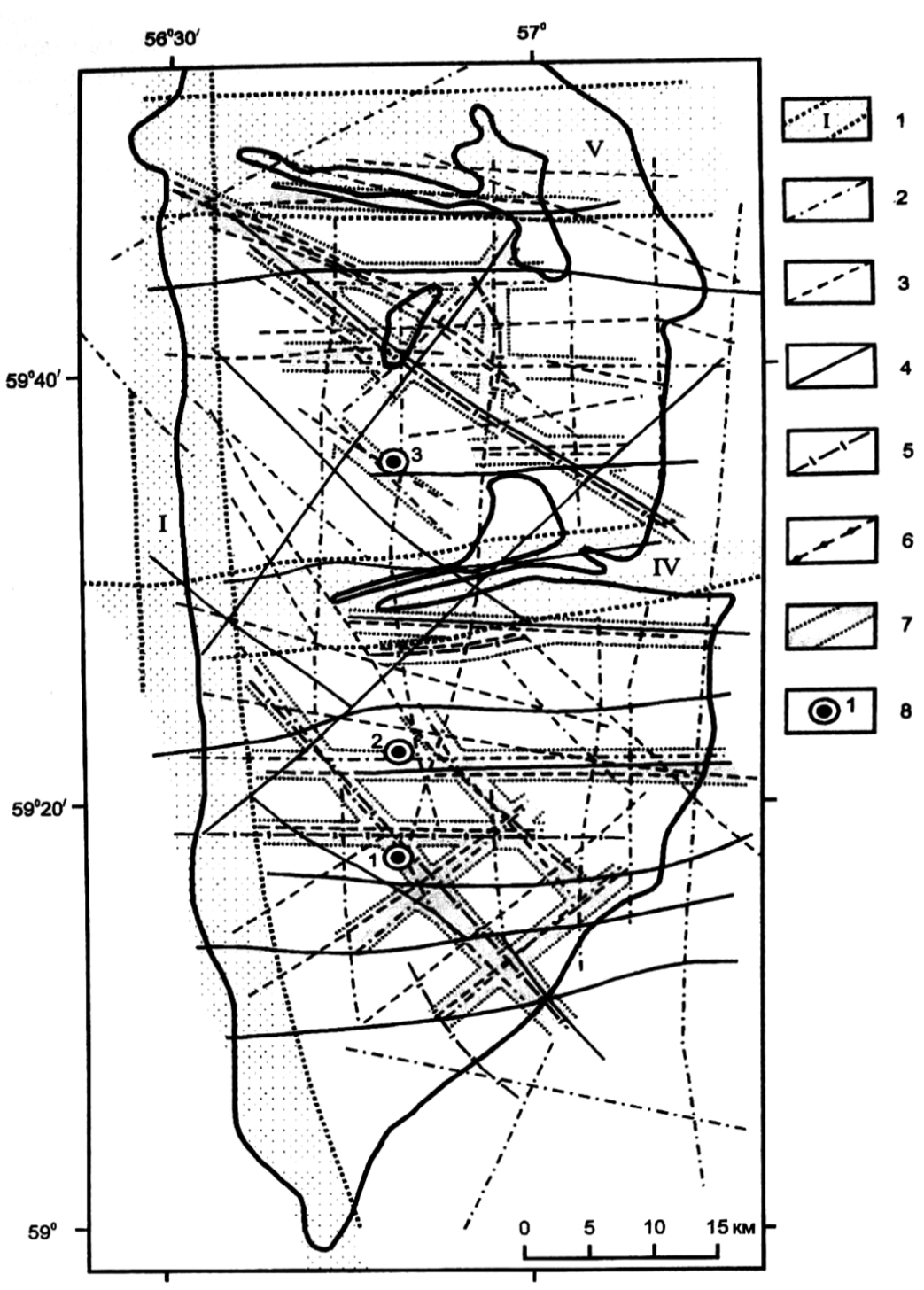

Рис. 2. Схема предполагаемых разрывных нарушений в пределах иентральной и южной частей калийной залежи ВКМС (Кудряшов А.И., 2001):

1 - Зонь Красноуфимского (I), Дуринского (IV) и Боровичкого (V) региональных разломов; оси зон локальных разрывов чехла и фундамента, вылеленные по данным гравиметрической и магнитометрической съемок (2), гравиметрической съемки (3), комплекса геофизических и геоморфологических исследований (4), сейсморазведки (5) и геологической съемки (6); 7 - зоны наиболее вероятных разрывных нарушений; 8 -участки техногенных провалов и их номера

Результаты откачек из скважин на Легчимском месторождении подземных вод, пробуренных в зонах разломов на разных элементах рельефа (по данным гидрогеологических съемочных работ)

\begin{tabular}{|c|c|c|c|}
\hline \multirow{2}{*}{ Положение скважин в рельефе } & \multirow{2}{*}{$\begin{array}{c}\text { Количество } \\
\text { скважин, шт. }\end{array}$} & $\begin{array}{c}\text { Дебит, л/с } \\
\frac{\text { min-max }}{\text { средний }}\end{array}$ & $\begin{array}{c}\text { Удельный } \\
\text { дебит, л/с } \\
\frac{\text { min-max }}{\text { средний }}\end{array}$ \\
\hline На речных долинах & & $\underline{6,4-26,0}$ & $\frac{0,62-20,2}{19,4}$ \\
\hline На междуречьях (склоны и водоразделы) & 5 & $\underline{0,22-2,82}$ & $\underline{1,3}$ \\
\hline
\end{tabular}




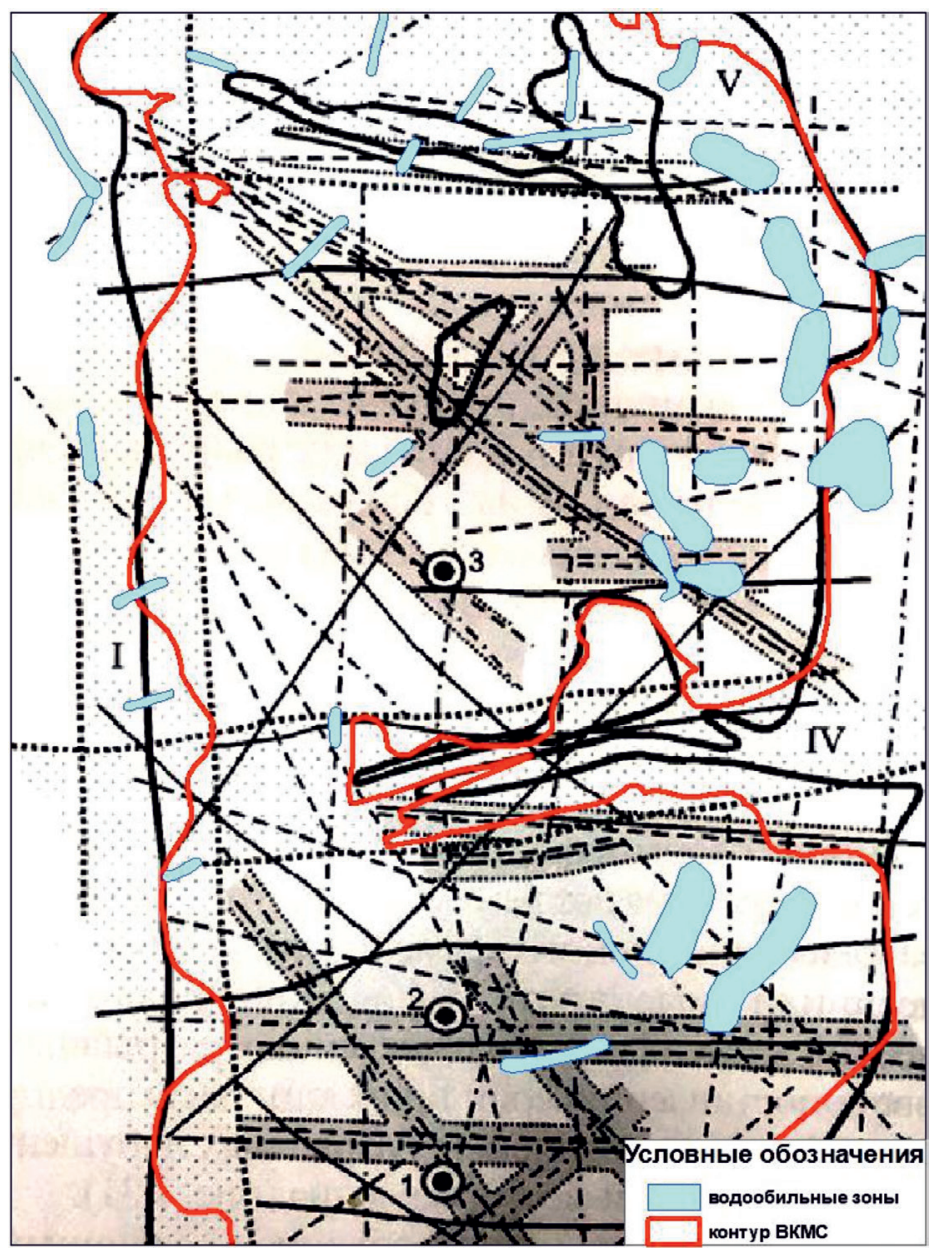

Рис. 3. Фрагмент схемы распределения водообильных зон терригенно-карбонатной толщи относительно разрывных нарушений в пределах ВКМС

Водообильные зоны терригенно-карбонатной толщи расположены по площади неравномерно, что обусловлено главным образом действием геодинамических и структурно-тектонических факторов. Так, например, И.С. Копылов в своих работах [1, 6] указывает на принадлежность водообильных зон к узлам пересечения крупных линеаментов, отождествляемых с тектоническими нарушениями и обуславливающими геодинамические активные зоны (ГАЗ). Такие зоны (ГАЗ) характеризуются, как правило, повышенной неотектонической активностью, трещиноватостью пород и отмечается повышенная их водоносность. Это подтверждается и результатами исследований, проведенных одним из авторов данной работы для изучения месторождений подземных вод, приуроченных к зонам повышенной трещиноватости, где успешно применялся методический комплекс гео- лого-геофизических и гидрогеологических работ на двух месторождениях подземных вод (Бахтинское и Мутницкое), расположенных в административных границах г. Кирова [7]. Месторождениями эксплуатируется северодвинский терригенный комплекс.

Стоит отметить, что разрывные нарушения в пределах Верхнекамского месторождения солей выделяются главным образом по результатам геофизических и дистанционных исследований. Доказать, что отмеченные при бурении солеразведочных скважин зоны повышенной трещиноватости и дробления фиксируют то или иное разрывное нарушение, как правило, не удается.

\section{Заключение}

Водообильные зоны являются неотъемлемой составной частью любого водоносного горизонта (комплекса). Анализ материалов съемочных и других работ показал, 
что разные авторы единодушно связывают происхождение водообильных зон с неотектоникой. В связи с этим выделенные зоны терригенно-карбонатной толщи следует рассматривать как тектоногенные водообильные зоны. По пространственному положению они однотипны и представляют собой локальные площадные зоны неглубокого заложения.

На территории Верхнекамья основные перспективы поисков подземных вод для обеспечения населения пресной питьевой водой связаны с водообильными зонами верхнесоликамского водоносного горизонта.

\section{Список литературы / References}

1. Копылов И.С. Поиски и картирование водообильных зон при проведении гидрогеологических работ с применением линеаментно-геодинамического анализа // Научный журнал КубГАУ. 2013. № 93 (09). С. 1-12.

Kopylov I.S. Searches and mapping of the water-bearing zones during hydrogeological works with application of the lineament and geodynamic analysis // Nauchnyj zhurnal KubGAU. 2013. № 93 (09). P. 1-12 (in Russian).

2. Кудряшов А.И. Верхнекамское месторождение солей. Пермь: ГИ УрО РАН, 2001. 429 с.

Kudryashov A.I. Upper-Kama salt deposit. Perm: GI UrO RAN, 2001. 429 p. (in Russian).

3. Иконников Е.А., Катаев В.Н., Ермолович И.Г. Повышение эффективности выявления водообильных трещинных зон в фациально-невыдержанных песчано-глинистых толщах // Комплексные проблемы гидрогеологии: материа- лы науч. конф. СПб.: Санкт-Петербургский гос. ун-т, 2011. C. $72-74$.

Ikonnikov E.A., Kataev V.N., Ermolovich I.G. Increased efficiency of detection of the high water saturation crack zones in facial-non-retained sand-clay strata // Kompleksnie problemy gidrogeologii: materialy nauch. konf. St. Petersburg: St. Petersburg st. un-t, 2011. P. 72-74 (in Russian).

4. Иконников Е.А., Джаббаров А.Х. О водоносности нарушений Верхнекамского месторождения солей // Геология и полезные ископаемые Западного Урала. Пермский гос. нац. иссл. ун-т. Пермь. 2011. С. 144-146.

Ikonnikov E.A., Dzhabbarov A.Kh. On the water content of disturbances in the Upper-Kama salt deposit // Geologiya $\mathrm{i}$ poleznie iskopaemie Zapadnogo Urala. Permskij gos. nac. issl. un-t. Perm. 2011. P. 144-146 (in Russian).

5. Шерстнев В.А. Водообильные зоны. Избранные труды. Пермь: Изд-во ПГУ, ПСИ, ПССГК, 2002. 132 с.

Sherstnev V.A. High water saturation zones. Selected works. Perm: Izd-vo PGU, PSI, PSSGK, 2002. 132 p (in Russian).

6. Копылов И.С. Основные водоносные комплексы Пермского Прикамья и перспективы их использования для водоснабжения // Успехи современного естествознания. 2014. № 9. C. 105-110.

Kopylov I.S. Basic aquifers Perm Prikamye and prospects of their use for water supply // Uspekhi sovremennogo yestestvoznaniya. 2014. № 9. Р. 105-110 (in Russian).

7. Бычков С.Г., Катаев В.Н., Митюнина И.Ю., Степанов Ю.И. Разработка комплекса геолого-геофизических методов для выделения водообильных участков // Вестник Пермского университета. 2018. Т. 17. № 4. С. 379-385. DOI: 10.17072/psu.geol.17.4.379.

Bychkov S.G., Kataev V.N., Mityunina I.Yu., Stepanov Yu.I. Development of a complex of geological and geophysical methods of allocation of the water areas // Vestnik Permskogo universiteta. 2018. T. 17. № 4. P. 379-385 (in Russian). DOI: 10.17072/psu.geol.17.4.379. 